\title{
Seroprevalence and risk factors of Toxoplasma gondii infection in pregnant women from Bobo Dioulasso, Burkina Faso
}

\author{
Sanata Bamba ${ }^{1}$, Mamoudou Cissé ${ }^{1 *}$, Ibrahim Sangaré ${ }^{1}$, Adama Zida ${ }^{2}$, Souleymane Ouattara ${ }^{1}$ \\ and Robert T. Guiguemdé2
}

\begin{abstract}
Background: Toxoplasmosis is one of the common worldwide parasitic zoonosis due to Toxoplasma gondii (T. gondii). Toxoplasmosis during pregnancy can result in fetal and neonatal death or various congenital defects. The aim of this study was to assess the seroprevalence and risk factors of $T$. gondii infection in pregnant women following antenatal care (ANC) services at Bobo Dioulasso.

Methods: A cross-sectional study was conducted enrolling a sample of 316 pregnant women attending ANC at centers for maternal and child health of Bobo-Dioulasso town from March 2013 to February 2014. Data on sociodemographic and potential risk factors were collected from each study participant using structured questionnaire through face-to-face interview. Moreover, venous blood specimens were collected and tested for IgM and IgG antiT. gondii antibodies by enzyme-linked immunosorbent assay and enzyme linked fluorescent assay, respectively. Multivariable logistic regression modeling was used to identify the potential predictor variables for $T$. gondii infection.

Results: The overall seroprevalence for T. gondii infection was 31.1\% (98/316). All the pregnant women were positive for IgG anti-bodies exclusively. Multivariable logistic regression analysis showed that having at least a secondary education level (AOR $=2.23 ; 95 \% \mathrm{Cl}$ : [1.04-4.63]); being urban resident (AOR $=2.81 ; 95 \% \mathrm{Cl}$ : [1.24-6.86]) and the consumption of meat combination (pork + beef + mutton + wild meat + poultry) (AOR = 4.00; 95\% Cl: [1. 06-15.24]) were potential risk factors of $T$. gondii infection.

Conclusion: Toxoplasmosis is frequent in pregnant women and studies that show incidence of $T$. gondii among the neonates have to be done to introduce routine antenatal screening program to control congenital toxoplasmosis. There is the need for preventive measures such as education of pregnant women about the transmission routes and prevention methods of toxoplasmosis at ANC clinics.
\end{abstract}

Keywords: Toxoplasma gondii, Seroprevalence, Pregnant women, Risk factors, Burkina Faso

\section{Background}

Toxoplasmosis is one of the common worldwide parasitic zoonosis, caused by an obligate intracellular protozoan parasite Toxoplasma gondii [1]. Felines are the only definitive host while all other warm-blooded animals including humans are intermediate hosts for the parasite [2]. T. gondii is commonly transmitted to humans by

\footnotetext{
* Correspondence: cisse_m@yahoo.fr

'Université polytechnique de Bobo-Dioulasso, 01 BP 390, Centre MURAZ,

Bobo-Dioulasso, Burkina Faso

Full list of author information is available at the end of the article
}

accidental ingestion of oocyst stage of the parasite in water, food or soil contaminated with cat's faeces, or by eating raw or undercooked meat containing oocysts [2, 3 ]. It can also be transmitted congenitally during pregnancy [4]. In addition, other infectious pathways include blood transfusion, and organs transplantation [5]. Toxoplasmosis is more common in areas with tropical and very humid climates which are favorable conditions for the maintenance and dissemination of the oocysts [6].

Toxoplasmosis is a major public health problem in the world. Indeed, it is estimated that about one third of the 
World's population is infected with $T$. gondii. Although usually asymptomatic, it can result during pregnancy in fetal and neonatal death or various congenital defects [7] especially when the congenital infection occurs during the first trimester due to acute infection during pregnancy.

In Africa, the seroprevalence of $T$. gondii during pregnancy is generally as high as $80 \%[3,8]$. Moreover, presence of domestic cat at home [3], contact with cat and gardening soil [8] were found to be the main risk factor toxoplasmosis during pregnancy.

In Burkina Faso, the seroprevalence of toxoplasmosis during pregnancy have been poorly reported [9-11] and none of those previous reports had assessed risk factors for toxoplasmosis. This study sought therefore to determine the seroprevalence of $T$. gondii and to identify the potential risks factors associated with of $T$. gondii infection among pregnant women following ANC services at Bobo Dioulasso, the second largest city of Burkina Faso.

\section{Methods}

\section{Study area and period}

This study was conducted in Bobo-Dioulasso town from March 2013 to February 2014. Bobo-Dioulasso is the second biggest city of Burkina Faso located in the Southwest of the country with an estimated population of 1.7 million inhabitants. The climate is subtropical and humid with an average annual temperature above $20^{\circ} \mathrm{C}$. Agriculture (e.g., corn, millet, sorghum, peanuts, rice, cotton, vegetables) and livestock (poultry and cattle) is the main economic activity. Also, water supply system is made of natural source and drilling. Once collected, water will undergo several types of treatment depending on their origin so that it can be suitable for consumption and is then distributed to the population according to standards set by the World Health Organization (WHO). Overall 5000 pregnant women attended the ANC clinics per year with an estimated birth rate of 43.6 $\%$ [12]. There was no serological screening of pregnant women for $T$. gondii infection in Bobo-Dioulasso town and Burkina Faso in general.

\section{Study design and population}

We carried out a cross-sectional study enrolling a sample of 316 pregnant women attending ANC at centers for maternal and child health of Bobo-Dioulasso town from March 2013 to February 2014. Sample size was determined using single population proportion formula with seroprevalence value $(p=30.0 \%)$ taken from previous study (10) and 95\% confidence interval (CI) with a $5 \%$ desired absolute precision was considered. A systematic random sampling technique was used to obtain the required sample.

\section{Questionnaire survey}

Pregnant women were interviewed to collect data about the potential risk factors for toxoplasmosis by using structured questionnaire. The questionnaire covered socio-demographic information including age, level of education, occupation, residence (urban area versus rural area of Bobo-Dioulasso town (i.e. those who are living in the suburb of the city)), source of drinking water, and obstetric history and other behavioral factors like consumption of meat and milk. Furthermore, presence of domestic cats in their home was addressed.

\section{Samples collection and serological analysis}

After signing informed consent, $10 \mathrm{~mL}$ of venous blood were collected from each pregnant women in the tube coated EDTA. Each tube was centrifuged at $3000 \mathrm{rpm}$ for $10 \mathrm{~min}$ to remove plasma that was frozen at $-20{ }^{\circ} \mathrm{C}$ until use.

Serogical diagnosis of toxoplasmosis was performed using both immunoglobin G (IgG) and immunoglobulin $M$ (IgM) antibodies determination from sera in the Laboratory of Parasitology and Mycology of the Sourou Sanou teaching hospital of Bobo-Dioulasso. Sera were analysed using a standard Enzyme-linked immunosorbent assay (ELISA) commercial Kit (AxSYM), Abbott, Laboratoiries, Abbott Park, III, USA) and according to the manufacturer's instructions. A titer of IgG anti-Toxoplasma antibody $\geq 3 \mathrm{IU} / \mathrm{ml}$ was considered as positive in this study [13]. In order to confirm the first results, new samples were collected after 21 days.

Quantitative determination of specific IgM antibodies was performed using the enzyme linked fluorescent assay (ELFA) based on the VIDAS System (bio MérieuxLyon, France). IgM concentration > 0.65 index was used as reference value for positive results. Samples were considered reactive for $\operatorname{IgM}$ when the antibody concentration was greater than or equal to 0.6 index, non-reactive when the concentration was equal to 0 index, and undetermined when the concentration was between 0.4 and 0.5 index.

IgG avidity index was measured using the VIDAS System (bio Mérieux-Lyon, France) and results were interpreted according to the manufacturer's instructions with the reference value for high avidity i.e., IgG > 0.3 [14].

\section{Data analysis}

Data were coded and entered into Epidata 3.1 software. Data were thereafter imported to statistical STATA 12 (Stata Corp, College Station, TX, USA), cleaned before performing analyses. Cross-tabulations of sero-status were done with socio-demographic and behavioral characteristic as summary measures.

Univariate logistic regression was used as bivariate analysis to select significant variables to be used in 
subsequent multivariable logistic regression analysis. Multivariable logistic regression analysis was used to calculate adjusted odds ratios (AOR) and computed their $95 \%$ CI. Variables resulting in $p$-values less than 0.05 was considered to be significantly associated with seroprevalence of toxoplasmosis.

\section{Ethical considerations}

Ethical clearance was obtained from the National Research Ethical Committee from Burkina Faso (number 0123/10). Informed written consent was sought from each pregnant woman prior to involvement in the study. Information collected from each study participant was kept confidential and venous blood specimens collected were preserved anonymously.

\section{Results}

Seroprevalence of $T$. gondii infection

A total of 316 pregnant women were enrolled during the study period with the mean age \pm standard deviation (SD) of $26.9 \pm 4.2$ years. The prevalence of specific antiT. gondii IgG was of $31.1 \%$ (98/316). No IgM antibodies for $T$. gondii were found. All cases with Toxoplasmaspecific antibodies presented high avidity indexes.

Risk factors associated with $T$. gondii infection

In univariate analysis only non-housewives $(\mathrm{OR}=2.05$; 95\% CI: [1.18-3.57]), women with at least secondary education level $(\mathrm{OR}=2.12 ; 95 \% \mathrm{CI}$ : [1.07-4.18]) and those living in urban areas of Bobo-Dioulasso town $(\mathrm{OR}=2.41 ; 95 \% \mathrm{CI}:[1.07-5.42])$ were at higher odds of T. gondii infection (Table 1). In addition, consumption

Table 1 Univariate analysis of Toxoplasma seroprevalence in relation to socio-demographic characteristics among the pregnant women $(n=316)$ in Bobo-Dioulasso town

\begin{tabular}{|c|c|c|c|}
\hline Variable & Toxoplasma seroprevalence & Crude OR, Cl 95\% & $P$-value \\
\hline \multicolumn{4}{|l|}{ Age category Age } \\
\hline $17-19$ & $32.7(18 / 55)$ & 1 & - \\
\hline $20-29$ & $32(68 / 212)$ & $0.96[0.40-1.78]$ & 0.87 \\
\hline$>30$ & $35.3(12 / 34)$ & $0.97[0.39-2.44]$ & 0.97 \\
\hline \multicolumn{4}{|l|}{ Occupation } \\
\hline Housewife & $27.8(64 / 230)$ & 1 & - \\
\hline Others $^{a}$ & $48.6(34 / 70)$ & $2.05[1.18-3.57]$ & 0.01 \\
\hline \multicolumn{4}{|l|}{ Education level } \\
\hline Illiterate & $28.2(49 / 174)$ & 1 & - \\
\hline Primary & $35.4(29 / 82)$ & $1.17[0.66-2.10]$ & 0.56 \\
\hline At least secondary & $45.5(20 / 44)$ & $2.12[1.07-4.18]$ & 0.03 \\
\hline \multicolumn{4}{|l|}{ Marital statut } \\
\hline Married & $32.3(81 / 251)$ & 1 & - \\
\hline Unmarried & $36.1(17 / 47)$ & $0.71[0.34-1.47]$ & 0.36 \\
\hline \multicolumn{4}{|l|}{ Residence } \\
\hline Rural areas & $30.6(27 / 88)$ & 1 & - \\
\hline Urban residence & $33.5(71 / 212)$ & $2.41[1.07-5.42]$ & 0.03 \\
\hline \multicolumn{4}{|l|}{ Number of gravida } \\
\hline One & $22.2(10 / 45)$ & $1-$ & - \\
\hline More than one & $34.4(88 / 256)$ & $1.34[0.77-2.23]$ & 0.29 \\
\hline \multicolumn{4}{|l|}{ Water supply } \\
\hline General distribution & $32.3(94 / 291)$ & 1 & - \\
\hline Bottled water & $3.33(1 / 3)$ & $1.10[0.10-11.26]$ & 0.94 \\
\hline Other source ${ }^{b}$ & $60.0(3 / 5)$ & $3.31[0.53-20.06]$ & 0.20 \\
\hline \multicolumn{4}{|l|}{ Presence of cat at home } \\
\hline No & $29.6(75 / 253)$ & 1 & - \\
\hline Yes & $48.9(23 / 47)$ & 1.75 [0.92-3.32] & 0.08 \\
\hline
\end{tabular}

${ }^{\mathrm{a}}$ students, employees and unemployed; ${ }^{\mathrm{b}}$ Well or pond 
of meat combination (pork + beef + mutton + bush meat + poultry) was significantly associated with $T$. gondii seroprevalence $(\mathrm{OR}=4.78 ; 95 \% \mathrm{CI}$ : $[1.31-17.30])$ (Table 2).

Finally, the result of multivariable logistic regression analysis showed that having at least secondary education level (AOR $=2.23$; 95\% CI: [1.04-4.63]); urban residence $(\mathrm{AOR}=2.81 ; 95 \% \mathrm{CI}:[1.24-6.86])$ and the consumption of meat combination (pork + beef + mutton + wild meat + poultry) $(\mathrm{AOR}=4.00 ; 95 \% \mathrm{CI}$ : $[1.06-15.24])$ were potential risk factors of $T$. gondii infection (Table 3).

\section{Discussion}

The prevalence of anti-T. gondii IgG antibodies observed in this study (31.1\%) was consistent with previous findings reported in pregnant women from urban areas of Burkina Faso and ranged from 28.3\% to 31\% [9-11]. Our result was lower than those reported in Ghana (92.5\%) [15] and in Ethiopia (higher than 68\%) [3, 8, 16, 17]. However, lower seroprevalence of $T$. gondii was reported in many European countries and the United States of America [18]. Such seroprevalence variations could be due to differences in climatic conditions (dry climate, rainfall, temperature, soil type, altitude) and mothers' characteristics such as management of cats, educational level, hygienic practice and feeding habit [3, 8 , 17]. Furthermore, differences in serological methods used and the sensitivity difference could explain such discrepancy $[8,17]$.

All the pregnant women were positive for IgG antibodies exclusively suggesting either past infection or acquired immunity. Thus, they were not likely able to infect their fetus outside a context of high immunosuppression $[6,19]$.

In this study high education level, being urban resident and the consumption of meat combination (pork + beef + mutton + wild meat + poultry) were identified as possible risk factors associated with $T$. gondii infection. Women with high education level were more likely to consume meat combination (pork + beef + mutton + wild meat + poultry) probably due to their high income and were therefore more exposed to $T$. gondii infection. Our findings suggest the need for preventive measures such as education of pregnant women about the transmission routes and prevention methods of toxoplasmosis at ANC clinics. However, a previous study in Ethiopia showed that women who cannot read and write were 5 times more likely to acquire $T$. gondii infection than those who had tertiary level of education [17]. In Brazil, pregnant women with low educational status had higher seroprevalence of T. gondii [20]. Moreover, reports from Netherlands and USA, showed that the seroprevalence of toxoplasmosis increases when the level of education decreases $[6,21]$.

Furthermore, the association between seroprevalence of $T$. gondii and urban residence of Bobo-Dioulasso town could be explained by insalubrity due to the demographic pressure in that town and dilapidation of water pipelines. Both factors are known to favor the survival of oocysts and to maintain a high prevalence of $T$. gondii infection [22-24]. Our results suggest the need for conducting further studies to better understand to what

Table 2 Univariate analysis of Toxoplasma seroprevalence in relation to behavioral characteristics among the pregnant women $(n=316)$ in Bobo-Dioulasso town

\begin{tabular}{|c|c|c|c|}
\hline Variable & Toxoplasma seroprevalence & Crude OR, 95\% Cl & $P$-value \\
\hline \multicolumn{4}{|l|}{ Type of meat consumed } \\
\hline Beef & $21.2(7 / 33)$ & 1 & - \\
\hline Mutton & $16.7(3 / 18)$ & $0.73[0.17-3.31]$ & 0.70 \\
\hline Poultry & $34.2(75 / 219)$ & $1.82[0.75-4.38]$ & 0.18 \\
\hline Pork & $28.6(4 / 14)$ & $1.49[0.35-6.20]$ & 0.59 \\
\hline Meat combination ${ }^{a}$ & $56.3(9 / 16)$ & $4.78[1.31-17.30]$ & 0.02 \\
\hline \multicolumn{4}{|c|}{ Frequency of meat consumption } \\
\hline Regular & $31.3(63 / 201)$ & 1 & - \\
\hline Irregular & $35.0(35 / 100)$ & $1.07[0.65-1.70]$ & 0.77 \\
\hline \multicolumn{4}{|l|}{ Degree of meat cooking } \\
\hline Well-cooked & $31.6(6 / 19)$ & 1 & - \\
\hline Undercooked & $32.6(92 / 282)$ & $1.01[0.37-2.75]$ & 0.98 \\
\hline \multicolumn{4}{|l|}{ Consumption of milk } \\
\hline No & $32.8(20 / 61)$ & 1 & - \\
\hline Yes & $32.5(78 / 240)$ & $0.96[0.51-1.72]$ & 0.87 \\
\hline
\end{tabular}

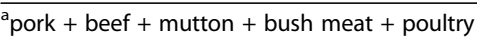


Table 3 Risk factors associated with Toxoplasma seroprevalence among the pregnant women $(n=316)$ in Bobo-Dioulasso town

\begin{tabular}{|c|c|c|c|}
\hline Variable & Toxoplasma seroprevalence & Adjusted OR 95\% Cl & $P$-value \\
\hline \multicolumn{4}{|l|}{ Occupation } \\
\hline Housewife & $27.8(64 / 230)$ & 1 & - \\
\hline Others & $48.6(34 / 70)$ & $1.83[1.0-3.40]$ & 0.05 \\
\hline \multicolumn{4}{|l|}{ Education level } \\
\hline Illiterate & $29.8(52 / 174)$ & 1 & - \\
\hline Primary & $31.7(26 / 82)$ & $1.10[0.61-2.00]$ & 0.75 \\
\hline At least secondary & $45.5(20 / 44)$ & $2.23[1.04-4.63]$ & 0.04 \\
\hline \multicolumn{4}{|l|}{ Residence } \\
\hline Rural areas & $27.3(24 / 88)$ & 1 & - \\
\hline Urban residence & $34.9(74 / 212)$ & $2.81[1.24-6.86]$ & 0.01 \\
\hline \multicolumn{4}{|l|}{ Presence of cat at home } \\
\hline No & $29.6(75 / 253)$ & 1 & - \\
\hline Yes & $48.9(23 / 47)$ & $1.61[0.81-3.18]$ & 0.16 \\
\hline \multicolumn{4}{|l|}{ Type of meat consumed } \\
\hline Beef & $21.2(7 / 33$ & 1 & - \\
\hline Mutton & $33.3(6 / 18)$ & $0.51[0.11-2.38]$ & 0.42 \\
\hline Poultry & $32.9(72 / 219)$ & $1.66[0.67-4.11]$ & 0.27 \\
\hline Pork & $28.6(4 / 14)$ & $1.04[0.24-4.48]$ & 0.96 \\
\hline Meat combination ${ }^{a}$ & $56.3(9 / 16)$ & $4.00[1.06-15.24]$ & 0.04 \\
\hline
\end{tabular}

apork + beef + mutton + bush meat + poultry

extend urban residence plays a role in the epidemiology of toxoplasmosis in Bobo-Dioulasso town.

In our study pregnant women consuming meat combination (pork + beef + mutton + wild meat + poultry) were significantly at greater risk of toxoplasmosis. This could be due to differences in the seroprevalence of $T$. gondii in the type of animals consumed in that town. Indeed, we previously reported a seroprevalence of $14.3 \%$ and $60 \%$ for both bovine and ovine toxoplasmosis in Bobo-Dioulasso town during the same period of the study [25, 26]. Altogether our data highlight the need for further studies aiming to assess the seroprevalence of $T$. gondii in domestic animals such pigs and poultry.

We do acknowledge some limitations to our study. First, risk factor assessment was done based on study participants' response which may suffer from recall bias. Second, since this study was heath centers based study, it may not represent the general population.

\section{Conclusion}

Toxoplasmosis is frequent in pregnant women and studies that show incidence of congenital infection among the neonates have to be done to introduce routine antenatal screening program to control congenital toxoplasmosis. Education level, being urban resident and the consumption of meat combination were identified as possible risk factors associated with $T$. gondii infection. There is the need for preventive measures such as education of pregnant women about the transmission routes and prevention methods of toxoplasmosis at ANC clinics. Further studies aiming to assess the seroprevalence of $T$. gondii in domestic animals are warranted.

\section{Abbreviation}

ANC: Antenatal care; AOR: Adjusted odds ratio; Cl: Confident interval; ELFA: Enzyme linked fluorescent assay; ELISA: Enzyme linked immunosorbent assay; IgG: Immunoglobulin G; IgM: Immunoglobulin M; WHO: World Health Organization.

\section{Acknowledgements}

Our sincere acknowledgements to all the study participants and the medical staff.

\section{Funding}

This study did not benefited from any specific grant or fund.

\section{Availability of data and materials}

The datasets analyzed during the current study is available from the corresponding author on reasonable request.

\section{Authors' contributions}

SB conceived, conducted the field study, and performed the serological analysis. MC analysed the data. SB and MC wrote the manuscript. IS, AZ, SO, and RTG critically revised the manuscript. All authors read and approved the final manuscript.

\section{Ethics approval and consent to participate}

Ethical clearance was obtained from the National Research Ethical Committee from Burkina Faso (number 0123/10). Informed written consent was sought from each pregnant woman prior to involvement in the study. 


\section{Consent for publication}

This part is not applicable because the manuscript contains no any individual person's data in any form (including individual details, images or videos).

\section{Competing interests}

The authors declare that they have no competing interests.

\section{Publisher's Note}

Springer Nature remains neutral with regard to jurisdictional claims in published maps and institutional affiliations.

\section{Author details}

'Université polytechnique de Bobo-Dioulasso, 01 BP 390, Centre MURAZ, Bobo-Dioulasso, Burkina Faso. ${ }^{2}$ Université Ouaga 1 Joseph-KI Zerbo,

Ouagadougou, Burkina Faso.

Received: 21 January 2017 Accepted: 30 June 2017

Published online: 11 July 2017

\section{References}

1. Tenter AM, Heckeroth AR, Weiss LM. Toxoplasma gondii: from animals to humans. Int J Parasitol. 2000;30:1217-58.

2. Dubey J. Toxoplasmosis - a waterborne zoonosis. Vet Parasitol. 2004;126(12):57-72.

3. Zemene E, Yewhalaw D, Abera S, Belay T, Samuel A, Zeynudin A. Seroprevalence of Toxoplasma gondii and associated risk factors among pregnant women in Jimma town, southwestern Ethiopia. BMC Infect Dis. 2012;12:337.

4. Wam EC, Sama LF, Ali IM, Ebile WA, Aghangu LA, Tume CB. Seroprevalence of Toxoplasma gondii $\lg \mathrm{G}$ and $\lg \mathrm{M}$ antibodies and associated risk factors in women of child bearing age in Njinikom. NW Cameroon BMC Res Notes. 2016:9:406.

5. CDC. Parasites-toxoplasmosis (Toxoplasma infection). 2014. https://www.cdc gov/parasites/toxoplasmosis. Accessed 26 Aug 2014.

6. Jones JL, Dargelas V, Roberts J, Press C, Remington JS, Montoya JG. Risk factors for Toxoplasma gondii infection in the United States. Clin Infect Dis. 2009;49(6):878-84

7. Lopes FM, Gonçalves DD, Mitsuka-Breganó R, Freire RL, Navarro IT. Toxoplasma gondii infection in pregnancy. Braz J Infect Dis. 2007;11:496506.

8. Abamecha F, Awel H. Seroprevalence and risk factors of Toxoplasma gondi infection in pregnant women following antenatal care at Mizan Aman general hospital, bench Maji zone ( BMZ ),Ethiopia. BMC Infect Dis. 2016;16: 460 .

9. Simpore J, Savadogo A, Ilboudo D, Nadambega MC, Esposito M, Yara J, et al. Toxoplasma gondii, HCV, and HBV seroprevalence and co-infection among HIV-positive and -negative pregnant women in Burkina Faso. J Med Virol. 2006;78(6):730-3.

10. Ouermi D, Simpore J, Belem AM, Sanou DS, Karou DS, Ilboudo D, et al. Coinfection of Toxoplasma gondii with HBV in HIV-infected and uninfected pregnant women in Burkina Faso. Pak J Biol Sci. 2009;12(17):1188-93.

11. Bamba S, Somer DA, Chemla C, Geers R, Guigemdé TR. Analyse sérologique de la toxoplasmose pergravidique : évaluation des risques et perspectives du dépistage prénatal au Centre Hospitalier Universitaire de Bobo Dioulasso au Burkina Faso. Pan Afr Med J. 2012;12:42.

12. Institut National de la Statistique et de la Démographie. Recensement général de la population et de l'habitation de 2006. 2006. http://www.insd. bf/n/index.php/publications?id=141. Accessed 29 Dec 2016.

13. Cimon B, Marty P, Morin O, Bessières MH, Marx-Chemla C, Gay-Andrieu F, et al. Specificity of low anti-Toxoplasma lgG titers with IMx and AxSYM Toxo IgG assays. Diagn Microbiol Infect Dis. 1998;32:65-7.

14. Pelloux $H$, Brun E, Vernet G, Marcillat S, Jolivet M, Guergour D, FrickerHidalgo H, Goullier-Fleuret A, Ambroise-Thomas P. Determination of antiToxoplasma gondii immunoglobulin $\mathrm{G}$ avidity: adaptation to the Vidas system (BioMerieux). Diagn Microbiol Infect Dis. 1998;32:69-73.

15. Ayi I, Edu A, Apea-Kubi K, Boamah D, Bosompem K, Edoh D. Seroepidemiology of toxoplasmosis amongst pregnant women in the greater Accra region of Ghana. Gh Med J. 2009:43:107-14.

16. Gelaye W, Kebede T, Hailu A. High prevalence of anti-toxoplasma antibodies and absence of Toxoplasma gondii infection risk factors among pregnant women attending routine antenatal care in two hospitals of Addis Abeba Ethiopia. Int J Infect Dis. 2015:34:41-5.

17. Agmas B, Tesfaye R, Koye DN. Seroprevalence of Toxoplasma gondii infection and associated risk factors among pregnant women in Debre Tabor, Northwest Ethiopia. BMC Res Notes. 2015;8:107

18. Pappas G, Roussos NFM. Toxoplasmosis snapshots: global status of Toxoplasma gondii seroprevalence and implications for pregnancy and congenital toxoplasmosis. Int J Parasitol. 2009;39:1385-94.

19. Jose GM, Remington JS. Management of Toxoplasma gondii infection during pregnancy. Clin Infect Dis. 2008;47:554-66.

20. Bittencourt LHFB, Lopes-Mori FMR, Mitsuka-Breganó R, Valentim-Zabott M, Freire RL, Pinto SB, et al. Seroepidemiology of toxoplasmosis in pregnant women since the implementation of the surveillance program of toxoplasmosis acquired in pregnancy and congenital in the western region of Paraná, Brazil. Rev Bras Ginecol Obs. 2012;34(2):63-8.

21. Kortbeek LM, De Melker HE, Veldhuijzen IK, Conyn-van Spaendonck MA. Population-based Toxoplasma seroprevalence study in The Netherlands. Epidemiol Infect. 2004;138:839-45.

22. Isaac-Renton JL, Bowie WR, King A, Irwin GS, Ong CS, Fung CP, et al. Detection of Toxoplasma gondii oocysts in drinking water. Appl Env Microbiol. 1998;64:2278-80.

23. Rahman H, Murugkar HV, Kumar A, Islam M, Mukherjee S. Seroprevalence of toxoplasmosis in a district of Assam, India. Indian J Public Health. 2008;52(1): 48-9.

24. El-Gozamy BR, Mohamed SA, Mansour HA. La toxoplasmose chez les femmes enceintes Qualyobia gouvernorat, en Egypte. J Soc Egypt Parasitol. 2009;39(2):389-401.

25. Bamba S, Cissé M, Tarnagda Z, Villena I, Guiguemdé TR. Enquête sérologique sur la toxoplasmose bovine à Bobo- Dioulasso, Burkina Faso. RASPA. 2013;11(3-4):193-7.

26. Bamba S, Faye B, Tarnagda Z, Boly N, Guiguemdé RT, Villena I. Séroprévalence de la toxoplasmose chez les ovins à Bobo-Dioulasso, Burkina Faso. Rev Elev Méd Vété Pays Trop. 2012:65(3-4):63-6.

\section{Submit your next manuscript to BioMed Central and we will help you at every step:}

- We accept pre-submission inquiries

- Our selector tool helps you to find the most relevant journal

- We provide round the clock customer support

- Convenient online submission

- Thorough peer review

- Inclusion in PubMed and all major indexing services

- Maximum visibility for your research

Submit your manuscript at www.biomedcentral.com/submit 